\title{
A CULTURA DO CONSUMO E A EROTIZAÇÃO NA INFÂNCIA
}

Ivone Maria dos Santos

Especializada em Mídia, Informação e Cultura. Texto produzido sob orientação do Prof. Dr. Dennis de Oliveira.

\section{Resumo}

Este artigo trata da importância da formação e desenvolvimento intelectual da criança relacionados ao papel da publicidade neste processo. Em tempos em que a atual indústria mercadológica dedica uma importância cada vez maior ao público infantil, é comum perceber que este público é um dos mercados mais visados nesta sociedade de consumo desenfreado. Os meios de comunicação muitas vezes usam das deficiências de julgamento e da ingenuidade das crianças em busca de lucros; inserindo-as de maneira precoce ao mundo adulto, deixando de lado questões que podem prejudicar o seu desenvolvimento como futuros cidadãos.

Palavras-chave: Propaganda; publicidade; público infantil; consumo; erotização

\begin{abstract}
This article deals with the importance of TRAINING and intellectual development of children related to the role of advertising in this process. In times when the current industry devotes an increasingly importance to children, it is common to realize that this public is one of the most targeted markets in this society. The media often takes advantage of the poor judgment and the ingenuity of children in search of profits, by placing them early in the adult world, leaving aside issues that may harm their development as future citizens.
\end{abstract}

Keywords: Propaganda; advertisement; children; consumption; eroticism

\section{Resumen}

Este artículo discute la importancia de la formación y el desarrollo intelectual de los niños relacionados con el papel de la publicidad en este proceso. En un momento en que la industria actual dedica cada vez más importancia para los niños, es común percibir que el público infantil es lo más planteado en esta sociedad de consumo. Los medios de comunicación utilizan a menudo las deficiencias del juicio y el ingenio de los niños en busca de ganancias, colocándolos de manera temprana al mundo de los adultos, dejando de lado cuestiones que pueden obstaculizar su desarrollo como futuros ciudadanos.

Palabras clave: Propaganda; publicidad; niños pequeños; consumo; erotismo 


\section{A CULTURA DO CONSUMO E A EROTIZAÇÃO NA INFÂNCIA}

\section{O consumismo}

Em quase todas as culturas conhecidas, com raras exceções de algumas subculturas $^{1}$, as pessoas geralmente possuíam objetos supérfluos, simbolizando satisfação emocional. No final do século 19 e início do século 20, famílias burguesas compravam muitos objetos com a finalidade de valorizar e enriquecer o ambiente doméstico e também trazer conforto para os membros da família. Com isso, estes bens eram repassados de pais para filhos, inspirando respeito e tornando-se uma tradição emocional e cultural; o consumismo então, foi se tornando, uma espécie de "prova" material da nobreza.

Com o passar dos tempos, tudo começou a mudar, o capitalismo ocidental estendeu para as massas o que antes era privilégio apenas das classes privilegiadas: a aquisição de bens. Essa prática acabou deixando de lado questões históricas e tradições familiares, tornando-se uma atitude muitas vezes banal, levando ao consumismo inconsciente, impensado.

Essa "virada" de valores começou por volta do século XX. De início, veio o ataque liberal, contestador e esquerdista à família, à repressão sexual, a opressão das mulheres, à educação das crianças e aos valores burgueses como um todo. Em seguida, veio a corrosão paulatina e arrasadora da publicidade nos meios de comunicação, regidos pelos interesses comerciais capitalistas. Acredita-se que a partir daí os objetos supérfluos começaram a deixar de ser apenas sinais de vida bem-sucedida na esfera do trabalho, da família ou da realização sentimental, para se tornarem também uma atividade robotizada, sem finalidade certa e com muito pouco apelo emocional (informação verbal). ${ }^{2}$

O consumo se faz necessário para a sobrevivência numa sociedade onde as pessoas precisam se manter limpas, vestidas, alimentadas, necessitam se locomover para estarem inseridas num contexto social. A partir do momento em que este consumo se torna uma prática associada ao exagero, ao supérfluo, a aquisição de produtos ou serviços sem necessidade e sem consciência, se trata do consumismo, que é um sistema baseado no consumo exagerado, e essa é uma prática que se vai adquirindo juntamente com o desenvolvimento do indivíduo como pessoa, pois ninguém nasce consumista. Vivemos numa sociedade capitalista que impõe uma cultura de que é preciso ter para ser, onde geralmente as pessoas são identificadas pelo que consomem e pelo que possuem. Desde criança, as pessoas vão seguindo modas, aderindo a marcas, absorvendo valores propostos, que acabam estimulando a idéia de que só é considerado cidadão, aquele que consome e segue padrões estabelecidos.

Em alguns casos, o ato de consumir vai então preenchendo lacunas na vida do indivíduo, seja ela afetiva ou financeira. A resposta desse ato vem transformando 


\section{A CUlTURA DO CONSUMO E A EROTIZAÇÃO NA INFÂNCIA}

até conceitos teoricamente afetivos em materiais, por exemplo, um presente tem seu valor baseado no preço, e não mais na intenção. Atentos a isso, existe um mercado oferecendo todo tipo de produto que se pode imaginar, vendendo sonhos e promessas de realizações e bem estar.

Mas o ato de consumir exageradamente também pode trazer conseqüências negativas à sociedade, pois muitas vezes o orçamento das famílias não é o suficiente para sustentar tal prática, podendo incentivar o aumento da violência por parte desses indivíduos que não tem uma renda compatível que permita adquirir certos produtos. Esses "excluídos", muitas vezes influenciados pela sociedade capitalista e pelos meios de comunicação que vendem a idéia de que pobres e ricos têm as mesmas facilidades e direitos na aquisição de bens e produtos, partem para a violência não para garantir necessidades básicas, mas para sustentar ao luxo de um tênis importado, a roupa de grife ou um celular moderno. Isso com a falsa ilusão de que tais produtos irão inseri-los a um mundo diferente de sua verdadeira realidade de vida. É a cultura de que serão medidos pelos bens que possuem perante a sociedade, dando-lhes a impressão da possibilidade de elevação social através do consumo de bens, criando muitas vezes, indivíduos marginalizados, consumistas e individualistas deixando de lado outros valores humanos.

\footnotetext{
"Aparentemente todos têm direito a tudo e a todos os produtos disponíveis no mercado, pois para que este tipo de organização social se sustente é necessário que o homem seja livre - livre para trabalhar, para circular, para comprar, para escolher, para viver enfim! (...) significa que o homem é um ser absolutamente livre para escolher e construir seu próprio destino." (PIETROCOLLA, 1989: 59).
}

Lembrando que o consumismo desenfreado também compromete o futuro do planeta, além da prática com compras impensadas e não sustentáveis, a sociedade está caminhando para um verdadeiro colapso dos bens naturais, pois o planeta acabará não suprindo à grande demanda de matéria prima para atender a ganância do consumismo das sociedades. Além de que, em consequência de tanto se consumir há o fortalecendo e o aumento da produção de lixo; quanto mais consumo, mais lixo, simples ação e reação.

\section{A propaganda e o consumidor}

O que impulsiona o indivíduo à aquisição de produtos é o seu valor de uso, a princípio acredita-se que só se compra aquilo que se necessita, entretanto a permanente criação de novas necessidades para o hábito de se consumir é requisito fundamental para garantir a sociedade de consumo.

As propagandas na realidade deveriam apresentar e informar às pessoas sobre 


\section{A CULTURA DO CONSUMO E A EROTIZAÇÃO NA INFÂNCIA}

os novos produtos e serviços, mas o que ocorre é que seu papel acaba transcendendo a sua função apenas informativa. Deste modo seu novo objetivo é supervalorizar esta propriedade da mercadoria, agregando valores que a tornam insubstituíveis. Apelos sexuais e emocionais são incorporados de modo a atrair e seduzir os consumidores. A publicidade ganha espaço indo além do poder de uso dos produtos, envolve o consumidor através de apelos sedutores, oferecendo sonhos de riqueza, poder e status. Tudo a partir das mensagens veiculadas pelos meios de comunicação de massa, transformando os bens supérfluos em bens vitais, ou seja, transforma o valor de troca em valor de uso, abastecendo o mercado de objetos, imagens e símbolos para que o consumidor compre com a ilusão de se tornar feliz.

O indivíduo por sua vez, vivencia essa realidade satisfeito, porque o consumo acaba preenchendo uma série de carências e sonhos que são próprios do ser humano, criados a partir de condições e imposições pré-determinadas. Ser consumidor é um dos papéis que as pessoas vão desempenhando na sociedade, em busca de expressões de si mesmas, pois a própria sociedade sugere: o que se possui, define a que classe social se pertence.

Fomos educados para consumir. Aprendemos desde criança que quanto mais dinheiro um indivíduo tiver, mais será sua possibilidade de consumir, de comprar coisas, crescendo o seu prestígio, pois nesta sociedade o poder corresponde à riqueza pecuniária. (PIETROCOLLA, 1989, p. 59).

A comunicação produzida para as grandes massas tem normalmente a função de captar suas fantasias, desejos, sonhos e "domesticá-los", isto é, fazem uso de linguagens e imagens despertando desejos e vontades.

Os meios de comunicação não só vendem, aumentam e abrem espaço para os produtos, mas também exercem outra função ao demonstrar modelos a serem seguidos, isto é, apresenta padrões físicos, estéticos, sensuais e comportamentais, enfim, situações da vida aos quais as pessoas devem se moldar, ditando regras que devem ser cumpridas durante toda a sua existência.

\section{Propaganda para a Infância}

"A criança é o pai dos homens, por isso precisa ter prioridade." (WORTH, William Words).

Tratar cada tipo de consumidor de maneira personalizada tem sido a estratégia dos meios de comunicação desde a criação até a venda final de um produto. Diante disso, vemos também, um novo nicho de público sendo explorado: o público infantil.

As crianças, indivíduos ainda em desenvolvimento e formação, são mais vul- 


\section{A CULTURA DO CONSUMO E A EROTIZAÇÃO NA INFÂNCIA}

neráveis aos apelos da mídia que os adultos, não sendo poupadas desta realidade do consumismo desenfreado. Entre os seis e sete anos de idade, a criança é alfabetizada formalmente, porém já sofreu vários tipos de influências da mídia.

$\mathrm{Na}$ era medieval, as crianças eram vistas como "adultos em miniatura", pois compartilhavam o mesmo ambiente social e informacional que os adultos, eram quase todos analfabetos, escolas eram raras já que a leitura era um privilégio restrito ao clero. Elas viviam em uma cultura da oralidade e quase não havia espaço para uma divisão entre infância e idade adulta, os valores e costumes sociais eram repassados às crianças diretamente, a partir do contato com os adultos, que não demonstravam grandes preocupações acerca da educação infantil.

A criação moderna da prensa tipográfica, associada à alfabetização socializada, veio mudar este quadro, passou-se a imprimir e publicar diversos livros, contendo saberes que se colocavam à disposição de quem soubesse ler.

Desta forma, surgiu um parâmetro claro e objetivo para diferenciar adultos e crianças: adultos, seriam aqueles que sabem ler e escrever; e crianças, aqueles que deveriam passar por um processo gradual e lento, até adquirirem este conhecimento.

A função da escola neste momento ganhou uma fundamental importância: atribuiu a tarefa de ensinar às crianças a via de acesso aos saberes que circulavam no mundo adulto, a alfabetização, e simultaneamente prepará-las para este mundo através da disciplina.

Baseado nessa revisão histórica da civilização ocidental pode-se concluir que as formas de se conceber a infância variam de tempo em tempo, de sociedade a sociedade. Muito além do fator biológico, que aponta para características anatômicas e fisiológicas específicas às crianças, cada contexto cultural é capaz de criar uma maneira particular de concepção de criança. O sentido e as formas de se relacionar com ela, e o próprio papel dela na sociedade, resultam de uma complexa rede de valores e regras predominantes nesta sociedade. (HAMANN, Fernanda Passarelli).

Na modernidade, a ascensão sócio-econômica da burguesia trouxe valores diferentes dos medievais, e um novo modelo de organização familiar. Ao pai, chefe da família caberia cumprir com obrigações de trazer o sustento ao lar através do trabalho remunerado, a mãe, caberia o cuidado da casa, dos filhos e do marido. Aos dois, caberia a função de amar, educar e investir neles perspectivas de futuro e de progresso dentro da sociedade.

Atualmente, este modelo familiar, parece estar em crise. O número de casais separados, mães e pais que criam seus filhos sem a ajuda de um cônjuge vêm cres- 


\section{A CULTURA DO CONSUMO E A EROTIZAÇÃO NA INFÂNCIA}

cendo. A mulher, não está mais só ligada às atividades domésticas, vem conquistando espaço cada vez maior no mercado de trabalho e, muitas vezes culpa-se por não dedicar aos filhos à atenção que deveria. No passado, elas eram "adultos em miniatura", hoje são vistas como consumidor potencial.

Tal situação tem todo um envolvimento familiar, pois as crianças muitas vezes são usadas como "iscas” para atrair os pais, elas não tem noção de caro e barato, e nem sempre a família pode atender as vontades de consumo do filho, e em situações como esta, é comum história de crianças, que de tão ansiosas para terem algo que muitas vezes os pais não podem lhe dar, chegam a ficar doentes, aumentando o estresse familiar. Em contrapartida existem situações em que os pais, em especial os que são separados ou trabalham fora, como foi citado anteriormente, movidos pelo sentimento de culpa de ausência, acabam cedendo aos desejos das crianças, como forma de compensação, ou seja, estão colaborando na construção de indivíduos consumistas.

Esse direcionamento ao público infantil vem crescendo a partir da década de $1.980^{3}$, é a partir desse momento que a indústria cultural passa a conceber o publico infantil como consumidor potencial, crescendo o número de programas televisivos. A TV, muitas vezes, faz o papel de uma conveniente "babá eletrônica", que mantém os filhos quietos enquanto os pais trabalham ou se ocupam com os afazeres domésticos.

Para situar vale lembrar programações infantis da época como: Palhaço Bozo, TV Criança, Balão Mágico, Xou da Xuxa, TV Fofão entre outros, e também o aumento de produtos e serviços direcionados às crianças.

A conquista de crianças não é uma tarefa tão difícil, utilizam-se personagens e desenhos famosos, brindes, inúmeras propagandas e promoções, um verdadeiro bombardeio publicitário.

De acordo com estudos realizados pelo Instituto Alana ${ }^{4}$ as estratégias mais comuns para induzir ao consumo no horário comercial são: a publicidade convencional; o licenciamento de personagens da TV e cinema para atrelar sua imagem ao produto; e brindes nos postos de venda - que muitas vezes, exigem complemento em dinheiro.

Segundo pesquisas do Ibope, o mercado de produtos destinados para crianças e adolescentes, movimenta hoje, cerca de 50 bilhões por ano no Brasil.

Como a televisão é a principal mídia utilizada pela publicidade, pode-se imaginar o impacto que ela causa sobre o público infantil, pelo fato da maioria das 


\section{A CUlTURA DO CONSUMO E A EROTIZAÇÃO NA INFÂNCIA}

crianças passarem em média 4 horas, 50 minutos e 11 segundos por dia assistindo à programação televisiva (segundo pesquisa realizada pelo Instituto Alana). Este dado coloca o Brasil em primeiro lugar no ranking mundial. As crianças sozinhas em casa são alvos perfeitos para muitos produtos de consumo. Um dos fatores preocupantes, é que essas crianças não estão sendo impactadas apenas por este tipo de mídia. Os meios de comunicação utilizam as mais variadas linguagens para seduzir seu público alvo seja em peças escritas, impressas, de TV ou internet. Desta forma, as crianças, cada vez mais estão sendo induzidas a consumir os mais variados tipos de produtos, levando muitas vezes, à obesidade pelo consumo de alimentos calóricos; atos de violência por influência de comerciais, programas e brinquedos violentos. Mas o consumidor infantil não tem sido alvo apenas desses problemas citados, um outro tipo de comportamento de risco à infância gira em torno do sexo.

\section{A erotização precoce na infância}

De acordo com a psicóloga Ana Olmos, em entrevista ao instituto Alana, a erotização é precoce quando acontece antes da fase em que a criança estaria dentro da faixa etária correta para determinado estímulo "considerando-se que, de acordo com o Estatuto da Criança e do Adolescente, uma pessoa de até 12 anos ainda é uma criança". Se algo que é sugerido ou estimulado e esteja fora dessa faixa etária, pode trazer problemas. Esse tipo de atitude é prejudicial e deixa a criança perdida, pois são informações de difícil compreensão que podem ter impactos negativos para ela.

Algumas campanhas publicitárias estimulam de forma precoce a erotização infantil; programas de televisão exploram a sexualidade das crianças através de concursos de danças com músicas e coreografias insinuantes, apresentadoras de programas posam nuas para revistas, maquiagens para crianças estão cada vez mais sofisticadas, bonecas com corpos magros, seios grandes e muitas trocas de roupas são vendidas para qualquer faixa etária, revistas exploram os corpos das crianças com roupas e acessórios que se adequariam ao público adulto, entre outras inúmeras situações.

A sociedade está diante de uma realidade em que os meios de comunicação utilizam alguns argumentos de erotização que costumam estar sempre além da idade indicada ao seu público infantil, ou seja, crianças não são mais apenas alvo do consumismo inconsciente, mas estão sendo inseridas de maneira precoce ao mundo adulto. Problema este, que não se restringe apenas ao fato desta "tendência" estar comprometendo uma etapa necessária da vida, que é a infância.

A estimulação para a sexualidade de maneira antecipada, também pode trazer sérios problemas psicológicos a médio e longo prazo nas crianças como: antecipação da menstruação nas meninas, gravidez precoce, doenças sexualmente transmissíveis, distúrbios alimentares, depressão, baixo desempenho escolar, banalização da sexua- 


\section{A CULTURA DO CONSUMO E A EROTIZAÇÃO NA INFÂNCIA}

lidade, pois o acúmulo de cenas sexuais na cabeça delas faz com que aprendam a ver o sexo de maneira banal, como uma prática que se deve fazer porque todos fazem, e não pelo significado pessoal que se possa ter, entre outras graves conseqüências como o aumento da pedofilia no mundo adulto.

\footnotetext{
"Tenho receios sobre a forma como o sexo e a sexualidade são mostrados na televisão hoje em dia. Não mostram o sexo por amor ou afeto - mas como um meio de adquirir poder. Tanto para os homens quanto para as mulheres. Que mensagem horrível de se transmitir para nossos filhos." (LINN, 2006: 161).
}

\section{Regulamentação publicitária voltada ao público infantil}

Atentos a essas situações, temos no Brasil alguns órgãos que fiscalizam e regulamentam os direitos das crianças e adolescentes; o Projeto Criança e Consumo do Instituto Alana, por exemplo, criado em 2.006, desenvolve atividades relacionadas ao fomento de uma consciência crítica na sociedade a respeito do consumo de produtos e serviços por crianças e adolescentes e, principalmente, atividades que buscam debater e apontar meios de minimizar os impactos negativos do consumismo no desenvolvimento infanto-juvenil.

As grandes preocupações do Projeto Criança e Consumo estão relacionadas com os resultados apontados como conseqüência do investimento maciço na mercantilização da infância e da juventude, a saber: o consumismo, a erotização precoce, a incidência alarmante de obesidade infantil, a violência na juventude, o materialismo excessivo e o desgaste das relações sociais, dentre outros.

Por conta disso, o Projeto Criança e Consumo trabalha para acabar com toda a comunicação mercadológica dirigida à criança no Brasil. Por comunicação mercadológica pode-se considerar qualquer atividade de comunicação comercial para a divulgação de produtos e serviços independentemente do suporte ou do meio utilizado, ou seja, além de anúncios impressos, comerciais televisivos, rádio e banners na internet, são exemplos de comunicação mercadológica as embalagens, as promoções, o merchandising e a forma de disposição de produtos em pontos-de-venda.

De acordo com o Estatuto da criança e do adolescente no Art. 17: "O direito ao respeito consiste na inviolabilidade da integridade física, psíquica e moral da criança e do adolescente, abrangendo a preservação da imagem, da identidade, da autonomia, dos valores, idéias e crenças, dos espaços e objetos pessoais."

\section{Análise de Produto e Propaganda}

A seguir, serão apresentados dois exemplos, sendo um de produto e outro de uma propaganda direcionados ao público infantil, e na seqüência segue algumas con- 


\section{A CULTURA DO CONSUMO E A EROTIZAÇÃO NA INFÂNCIA}

siderações a respeito da análise dos mesmos. Para esta análise foi feito um trabalho de pesquisa exploratória, com um grupo de crianças na faixa etária de 7 a 10 anos, com o objetivo de saber que tipo de conceito e interpretação o produto e a propaganda sugerem a elas.

\section{A boneca Barbie}

Criada em 1959 pela empresa de brinquedos Mattel, de tão vendida e conhecida no mundo, a boneca Barbie é considerada um ícone cultural, com direito à réplica no Museu de Cera de Grévin, em Paris.

As primeiras bonecas lançadas custavam cerca de US $\$ 3,00$; hoje uma Barbie pode custar até US $\$ 10$ mil; a cada 2 segundos uma boneca Barbie é comprada em algum lugar do mundo.

No Brasil, ela chegou em 1.982 e atualmente ocupa o primeiro lugar na categoria em vendas de bonecas no país. Antes, as bonecas vendidas ao público infantil simbolizavam ingenuidade e infantilidade, onde essas bonecas se contentavam com uma chupeta ou com um chocalho. Com a chegada da Barbie, houve uma mudança nessas escolhas, o que se pode ver, é que a Barbie é uma boneca que demonstra nunca estar contente, ela sempre precisa de algo mais, e acaba incentivando esse tipo de comportamento nas meninas, ou seja, influencia ao ato de se consumir cada vez mais. De acordo com a gerente de marketing Isabel Patrão, da empresa Mattel, a Barbie permite que as crianças possam sonhar ser o que quiserem e imaginarem, como o próprio slogan diz: "Barbie, tudo o que você quer ser".

Para alimentar a imaginação das meninas, diversas versões da boneca são lançadas retratando profissões, tipos de comportamentos, ditando modas e remetendo a idéia de uma mulher sensual com cintura fina, seios grandes e diversas trocas de roupas. Influenciando desta forma, ao estereótipo de uma vida padrão a ser seguida, como ter corpo esbelto, cuidar da aparência, fazer ginástica, uma ideologia nada infantil que também estimula essas crianças ao erotismo precoce. E não basta apenas adquirir a boneca, é preciso construir um cenário inteiro, são acessórios de beleza, carros, casas e uma infinidade de fantasias de consumo. Para se ter idéia, a Barbie já teve mais de um bilhão de pares de sapatos e outro bilhão de peças de roupas.

\section{Marisol - Outdoor Lilica Ripilica}

A empresa Marisol S.A., no intuito de divulgar a marca de vestuário Lilica Ripilica, destinada ao público infantil do sexo feminino, realizou uma publicidade mídia externa/outdoor, no mês de Abril de 2.008, exposto inicialmente em uma praça da cidade de Londrina/PR, que apresentava uma menina aparentemente com 4 ou 


\section{A CULTURA DO CONSUMO E A EROTIZAÇÃO NA INFÂNCIA}

5 anos de idade, deitada de lado em uma espécie de divã, trajada com saia e com as pernas levemente cruzadas. Em sua mão, trazia um doce coberto por açúcar, deixando marcas brancas em torno de sua boca. Tal imagem vinha acompanhada pela frase 'Use e se lambuze'. Analisando esse tipo de propaganda pode se dizer que a mesma enaltece a erotização precoce e deturpa a imagem da inocência infantil pela postura sensual da foto em combinação com o apelo "Use e se lambuze", sendo também um incentivo a pensamentos de pedofilia.

O que se vê nesta peça publicitária é um exemplo de mensagem que divulga conceitos dissociados da realidade, distorcendo etapas importantes no desenvolvimento das crianças, não sendo capazes de valorizar e preservar cenários que demonstrem expressões de valores afetivos, importando-se apenas em destacar mensagens muitas vezes de forma erotizadas e não apropriadas ao público infantil.

\section{Metodologia da Pesquisa}

A metodologia aplicada foi a pesquisa exploratória, com perguntas indiretas. Participaram da pesquisa, 7 crianças de 7 a 10 anos de idade, sendo 3 meninos e 4 meninas das classes C e D, residentes na cidade de Guarulhos, na Grande São Paulo. Foi usada a técnica projetiva, ou seja, uma forma não estruturada e indireta de perguntas ou situações que incentiva os entrevistados a projetarem suas motivações, atitudes ou sensações subjacentes sobre questões em estudo.

A técnica utilizada foi a resposta por figura, onde se representa uma figura ao entrevistado, pedindo-lhe que conte uma história descrevendo-a. Uma importante técnica de construção com crianças é o desenho, o qual foi utilizado nesta pesquisa.

As crianças foram chamadas individualmente para que não houvesse interferência ou influência na resposta individual. Foram mostradas duas fotos da boneca Barbie em diferentes situações e vestimentas, em uma delas, a boneca vestia um biquíni e estava de óculos escuros, e na outra foto, a boneca fazia pose ao lado de um boneco representando a figura masculina, os dois com roupas de festa.

Das meninas entrevistadas, todas possuíam uma Boneca Barbie, algumas delas eram imitações da original, todas tinham mais de uma troca de roupas, e os meninos disseram que suas irmãs também tinham uma ou mais bonecas Barbie em casa.

Foi apresentada também uma cópia reduzida do outdoor da peça publicitária da marca infantil Lilica Ripilica/Marisol, veiculada no ano de 2008, onde foi pedido que as crianças a observassem por alguns minutos. Foram mostradas as mesmas fotos para cada criança, e em seguida, foi pedido que fizessem um desenho relacionado com as imagens apresentadas. 


\section{A CULTURA DO CONSUMO E A EROTIZAÇÃO NA INFÂNCIA}

\section{Resultados dos desenhos}

Nas histórias contadas sobre a Barbie, todas as crianças optaram em dar seqüência da imagem do suposto casal de bonecos, ignorando a imagem onde a boneca pousava de biquíni. Ao pedir que fosse relatado o que haviam desenhado, percebe-se que transportam para o mundo imaginário, situações que vivenciam no dia-a-dia. Todas as crianças entenderam que se tratava de um casal de namorados e não apenas de amigos.

O menino (criança 1) respondeu que o desenho que ele fez, estava mostrando que o casal iria sair dali e iriam para uma festa "se conhecerem melhor".

$\mathrm{O}$ menino (criança 2) respondeu que eles iriam namorar e que mais tarde, talvez a Barbie iria ganhar flores. $\mathrm{O}$ interessante desses dois primeiros garotos, é que fizeram quase o mesmo tipo de desenho, mesmo sendo colocados para desenhar em ambientes separados um do outro.

O menino (criança 3) disse que o casal talvez fosse sair da suposta festa e iriam brincar, mas achava que depois disso, eles iriam "ficar juntos".

Uma das meninas, (criança 4) escreveu mesmo antes de desenhar, que a Barbie lhe dá imaginação sobre o que ela irá vestir, e comentou também que às vezes acha as roupas curtas para ela usar. Desenhou os bonecos se casando, e disse que gostaria de ter um vestido de noiva igual ao da Barbie.

A menina (criança 5) desenhou a Barbie em casa, trocando de roupas e maquiando-se, e respondeu de maneira informal que ela estava se arrumando porque havia marcado um encontro com o boneco da foto.

A menina (criança 6) disse que a seqüência do desenho, se referia a uma festa do casal de namorados, num bar com outras amigas e que a Barbie estava de cabelos soltos e bonitos e vestia uma mini-saia.

A última menina, a mais nova das entrevistadas, com 7 anos de idade (criança 7), disse que a Barbie saiu com o namorado e que chamou mais um casal de amigos.

Sobre a imagem da marca Lilica Ripilica, um dos garotos disse que a menina parecia feliz, mas que tinha jeito de menina chata e parecia não gostar de brincar; um deles não quis fazer desenho e nem comentar sobre o outdoor, enquanto que o último garoto fez o desenho de uma menina triste com os dizeres que sua mãe não a deixava brincar. 


\section{A CULTURA DO CONSUMO E A EROTIZAÇÃO NA INFÂNCIA}

Uma das meninas disse que gosta do jeito da menina se vestir, e que quando vai a alguma festa de aniversário, também gosta de usar roupas do mesmo estilo, imagina que a menina da foto, está sempre maquiada e bonita; a outra menina entrevistada, também desenhou a figura de uma garota diante de um espelho com alguns itens de maquiagem. As demais disseram que a menina da foto, tem jeito muito sério e talvez esteja triste, mas que a roupa é bonita.

\section{Considerações finais}

Apesar de se tratar de uma pequena amostra de pesquisa, percebe-se num primeiro instante, que a criança contemporânea segue as tendências da "pressa moderna", ignorando e estreitando atitudes e gestos que no passado era um processo longo, com rituais românticos e mágicos, onde os encontros afetivos se iniciavam primeiro com olhares, depois a aproximação e posteriormente um relacionamento entre os sexos opostos.

Por influências de situações corriqueiras, familiares e da mídia, as crianças estão crescendo mais cedo, abreviando fases de seu desenvolvimento. Isso sem falar na possibilidade de decepções geradas por envolvimentos superficiais, quando se "fica", muitas vezes existe a falta de afeto e respeito, e não é rara a iniciação de uma vida sexual precoce. Nos desenhos apresentados, se percebe que essas crianças quando se deparam com a imagem de duas pessoas, sexo feminino e masculino, associam rapidamente a algum tipo de encontro posterior a aquele momento. No caso apresentado da Barbie, a boneca já traz em si algumas referências que incentivam esse tipo de interpretação por parte das crianças, pois em seus variados estilos, tendências e sugestões de comportamentos, inspiram as meninas a fantasiarem e anteciparem algumas situações típicas da fase adulta. Percebe-se também que a imagem da boneca, leva à interpretação de um estilo de vida sociável, dinâmico e de sucesso.

A publicidade infantil também está levando a criança a esse entendimento, muitas vezes sugerindo o consumo de roupas que valorizam o corpo, acelerando a chegada da puberdade e contribuindo com a banalização do sexo. É válido acrescentar que com o incremento da era digital e ficando cada vez mais tempo diante da televisão, as crianças estão sendo "convidadas" a se tornarem adultas antes do tempo. Alguns programas específicos ao público infantil, as incentivam a representarem e imitarem astros famosos; as meninas principalmente, se inspiram em mulheres adultas e sensuais, onde muitas vezes os apresentadores dos programas se dirigem a elas como se realmente elas fossem mulheres e não crianças. Essas meninas, antes mesmo de chegarem à fase da adolescência, já vão assimilando a idéia de que é preciso ser bonita e sensual para serem aceitas e valorizadas perante a sociedade, desprezando outros valores. 


\section{A CUlTURA DO CONSUMO E A EROTIZAÇÃO NA INFÂNCIA}

No outdoor da Marisol / Lilica Ripilica todas as crianças entrevistadas, projetaram na menina da foto situações adultas, fazendo referências a festas, maquiagens e beleza.

Vale lembrar que o despertar precoce para a sexualidade não é resultado apenas dos exemplos citados, mas de todo um arcabouço mundial. A mesma sociedade que condena os crimes que envolvem a pedofilia, também acaba promovendo uma cultura que apóia a erotização precoce, seja através de produtos, roupas ou no incentivo a comportamentos que não condizem com a fase infantil. Nos tempos atuais, é cada vez mais comum se ver nas ruas e nas escolas, meninas com 6 anos de idade vestidas como se tivessem 20 , onde os pais se orgulham disso, apoiando esse tipo de comportamento nos filhos. A moda infantil é praticamente a mesma moda adulta, muitas vezes a própria mãe, é a promotora da antecipação das fases de desenvolvimento de suas filhas, projetando nelas a maneira de como gostaria de se vestir ou até mesmo de se comportar. Diante de uma sociedade cada vez mais permissiva nestas questões, já é possível sentir as conseqüências do "abrandamento" destes fatos, ou seja, as crianças que deveriam estar brincando ou se preparando para um futuro, estão sendo inseridas num mundo de sedução e exibicionismo.

Sociedade, pais e veículos de comunicação precisam refletir e se conscientizar sobre que tipo de iniciação e orientação sexual estão direcionando às suas crianças. A proposta não é reprimir manifestações típicas da fase em que elas estão vivendo e que venham a ser exteriorizadas, mas evitar os excessos de incentivo a situações que remetam a erotização precoce e que futuramente as levem à banalização do sexo. Situações ou cenas que demonstrem carinho não precisam ser proibidas, até porque se corre o risco de a criança crescer com a imagem de que o sexo é feio ou vergonhoso. O problema é que ultimamente existem inúmeros casos, principalmente na mídia televisiva em que os afetos estão associados mais à pornografia do que a qualquer tipo de sentimento, e esta é uma das falhas na TV e também na publicidade, não problematizar, apenas apresentar estereótipos de comportamentos. Afinal, é válido lembrar que certas situações de conquistas, intimidade e prazer voltados ao sexo, fazem parte do mundo dos adultos.

Se o desenvolvimento das fases de amadurecimento sexual for respeitado, a criança seguirá as etapas de maneira gradativa, pois é importante que ela esteja apta a adquirir novos conhecimentos de acordo com o seu grau de entendimento intelectual.

Abreviar etapas do desenvolvimento natural na fase infantil pode gerar frustrações e fazer com que, quando adulto, o indivíduo fique tentando em vão recuperar o tempo perdido. É preciso permitir que as crianças tenham a oportunidade de fazer suas escolhas no tempo certo e que aprendam com as experiências vividas e não com 


\section{A CULTURA DO CONSUMO E A EROTIZAÇÃO NA INFÂNCIA}

imposições pré-estabelecidas pela sociedade e pela mídia. Imposições estas, que podem afeta-las enquanto crianças e refletir posteriormente na sua fase adulta, interferindo desta forma, no desenvolvimento de cidadãos equilibrados e conscientes, pois a criança não deve ser tratada como um adulto em miniatura, mas um ser próprio com suas características e necessidades.

Portanto, faz-se necessário ter certos cuidados ao desenvolver produtos e mensagens publicitárias ao publico infantil, bem como o que essas mensagens sugerem. A intenção não é proibir ou isolar a criança dos fatos, mas é importante acompanhar e orientá-las quanto aos apelos publicitários, bem como saber quais tipos de programas elas assistem. Mesmo porque a televisão se faz presente em grande parte dos lares e constitui uma realidade onde é necessário aprender a conviver. Quando houver cenas de violência, uso de drogas ou banalização do sexo é importante ajudá-las a compreender o que estão vendo e mostrar toda a extensão do problema.

\section{Referências bibliográficas}

COSTA, Jurandir Freire. "O mal-estar da nossa civilização" in: "Revista Continente Multicultural”, Pernambuco, $\mathrm{n}^{\circ}$ 32, ago. 2003. Disponível em: http://jfreirecosta.si tes.uol.com.br/entrevistas/com_o_autor/nossa_civilizacao.html. Acesso em: 21 maio 2009.

ESTEVES, Acúrsio. “Overmundo". Salvador: 2007. Disponível em: http: //www.overmundo.com.br/overblog/midia-e-sexualidade-na-educacao-infantil-ii. Acesso em 01/06/2009

HAMANN, Fernanda Passarelli. "Erotização da infância: a história de uma nova forma de ser criança”. Disponível em: http://www.multirio.rj.gov.br/portal. Acesso em: 22 abr. 2009.

LINN, Susan. "Crianças do consumo: a infância roubada". São Paulo: Instituto Alana, 2006. $322 \mathrm{p}$. 


\section{A CULTURA DO CONSUMO E A EROTIZAÇÃO NA INFÂNCIA}

MARCONDES FILHO, Ciro. “Televisão a vida pelo vídeo". São Paulo: Moderna, 1995. $119 \mathrm{p}$.

. "A linguagem da sedução: a conquista das consciências pela fantasia". São Paulo: Com-Arte, 1985. $142 \mathrm{p}$.

PIETROCOLLA, Luci Gati. "Sociedade de consumo". São Paulo: Global Editora, 1989.

Site "Diga não à erotização infantil". Disponível em: http://diganaoaerotizacaoinfant il.com.br. Acesso em 22/06/2009

STEINBERG, Shirley R.; Kincheloe, Joe L. "Cultura infantil: a construção corporativa da infância". Rio de Janeiro: Civilização Brasileira, 2004. 415 p.

TRIGUEIRO, André. "Valorizando a vida". Disponível em: http://www.mundosuste ntavel.com.br/valorizando.asp. Acesso em: 20/05/2009

Site "Instituto Alana". Disponível em: http://www.institutoalana.org.br. Acesso em: $13 / 04 / 2009$

RESENDE, Lino. "Sociedade, pedofilia e infância", 2009. Disponível em: http: //linoresende.jor.br/tag/pedofilia/. Acesso em: 14/07/2009

\section{Notas}

${ }^{1}$ Subcultura é um grupo de pessoas com características distintas de comportamentos e credos que os diferenciam de uma cultura mais ampla da qual elas fazem parte. São pequenos "grupos" ou uma cultura não totalmente desenvolvida, grupos que cultivam preservam mesmas ideias relacionadas a estética, religiosa, ocupacional, política, sexual, ou por uma combinação desses fatores.

2 Parte da entrevista de Jurandir Freire a Revista Continente Multicultural, agosto de 2003.

${ }^{3}$ Revista Pesquisa Fapesp, setembro de 2007, p. 3-4.

${ }^{4}$ Organização sem fins lucrativos, criada em 1994, desenvolve atividades em prol da defesa dos direitos das crianças e dos adolescentes relacionadas a relações de consumo em geral, bem como ao excessivo consumismo ao qual são expostos. 
A CUlTURA DO CONSUMO E A EROTIZAÇÃO NA INFÂNCIA

\section{ANEXOS}

Imagens da "Boneca Barbie" e da peça publicitária "Lilica Ripilica” apresentadas às crianças:
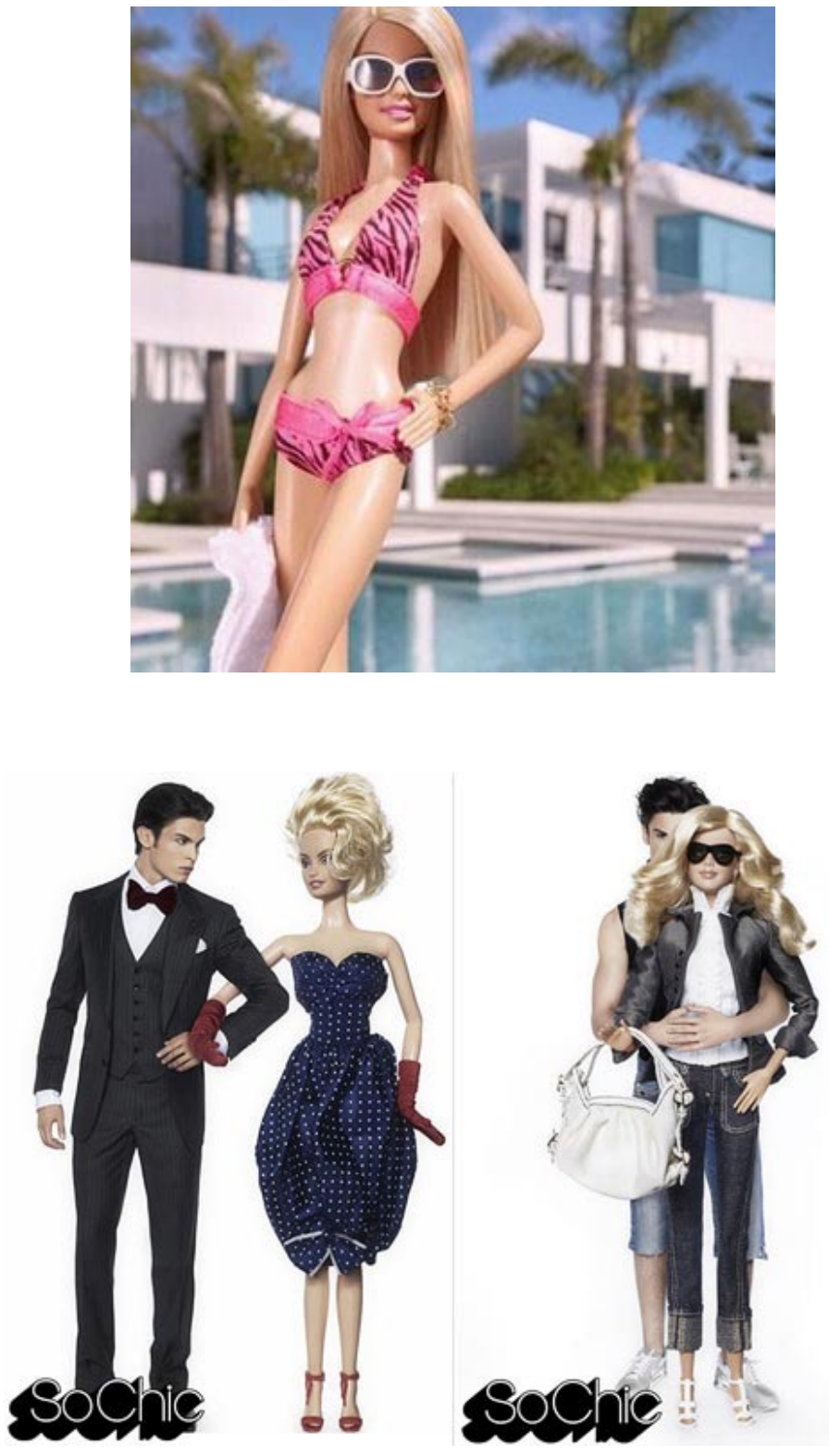
A CUlTURA DO CONSUMO E A EROTIZAÇÃO NA INFÂNCIA

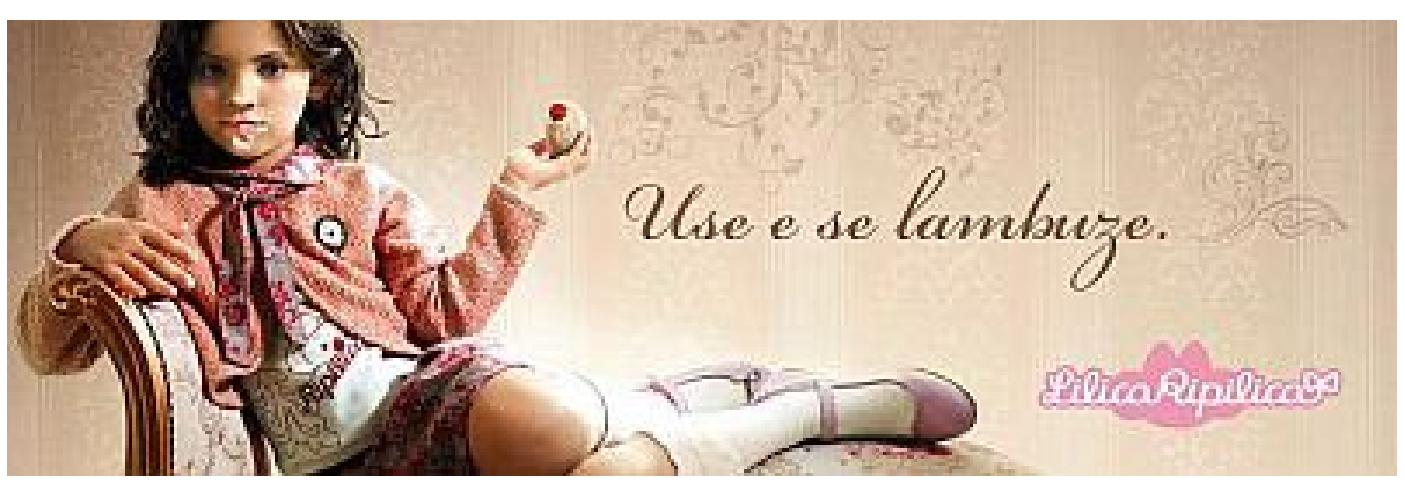

Desenhos apresentados pelas crianças entrevistadas:

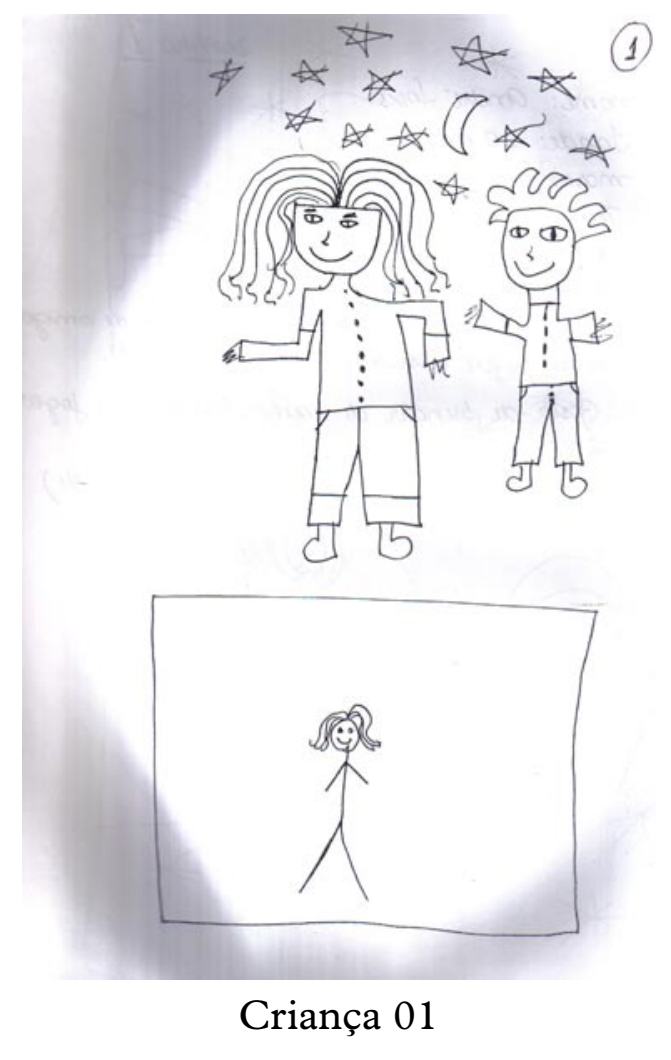


A CULTURA DO CONSUMO E A EROTIZAÇÃO NA INFÂNCIA

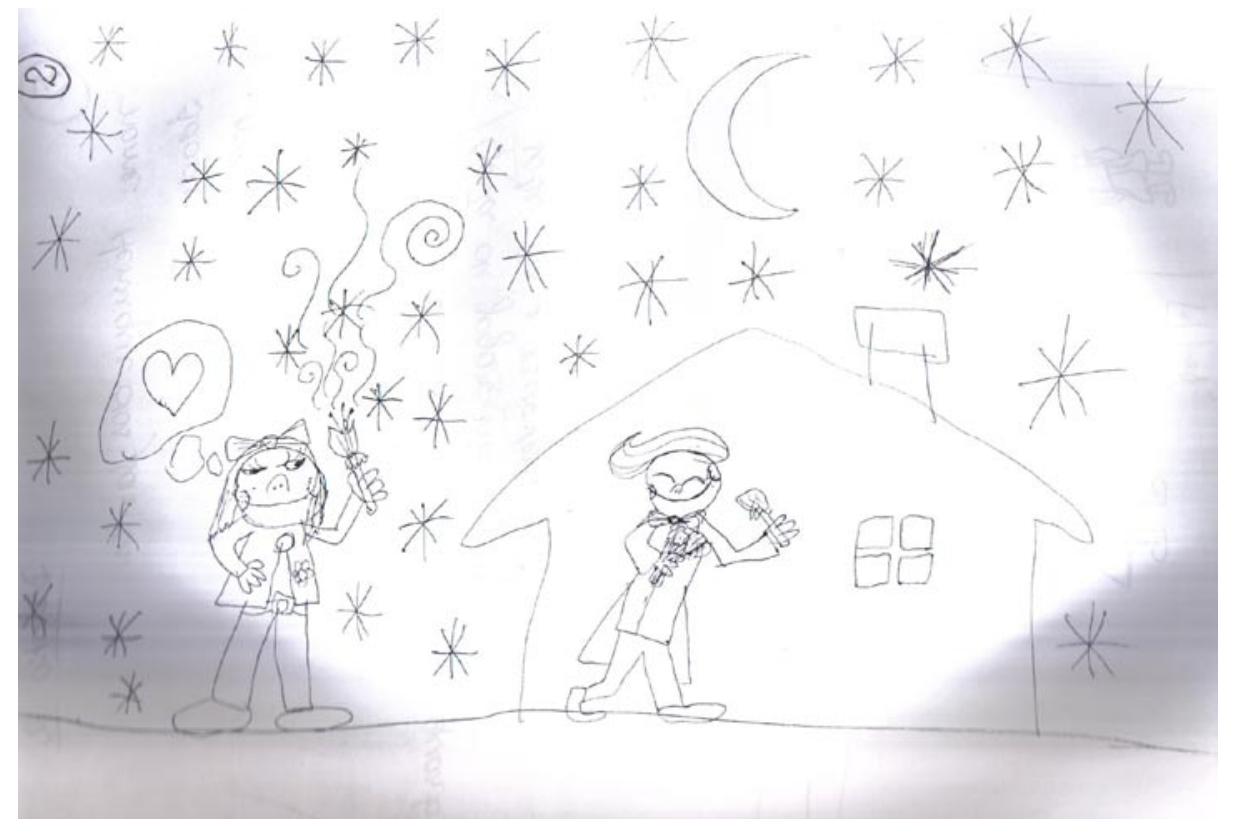

Criança 02

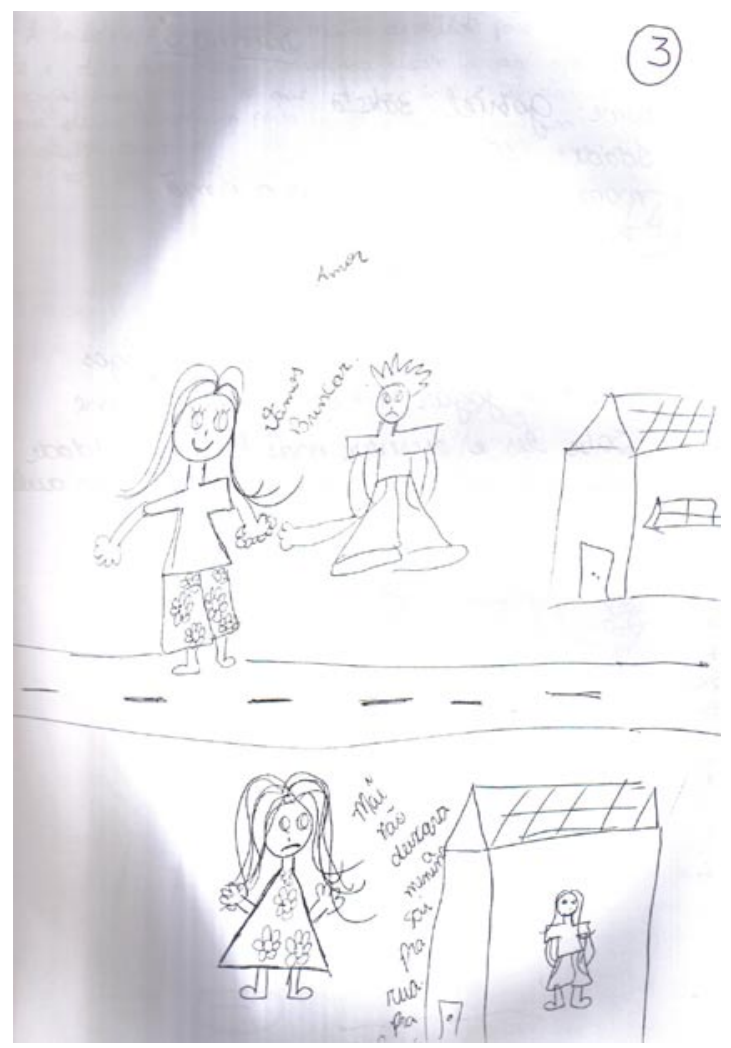

Criança 03 
A CUlTuRA do CONSUMO E A EROTIZAÇÃO NA INFÂNCIA

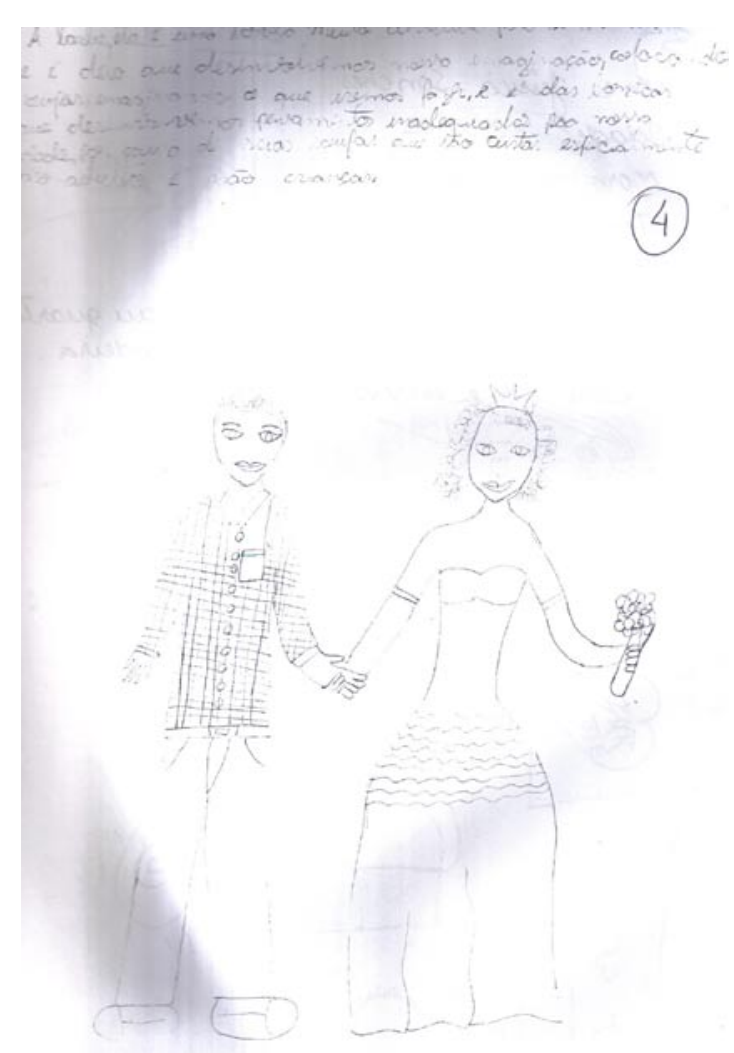

Criança 04

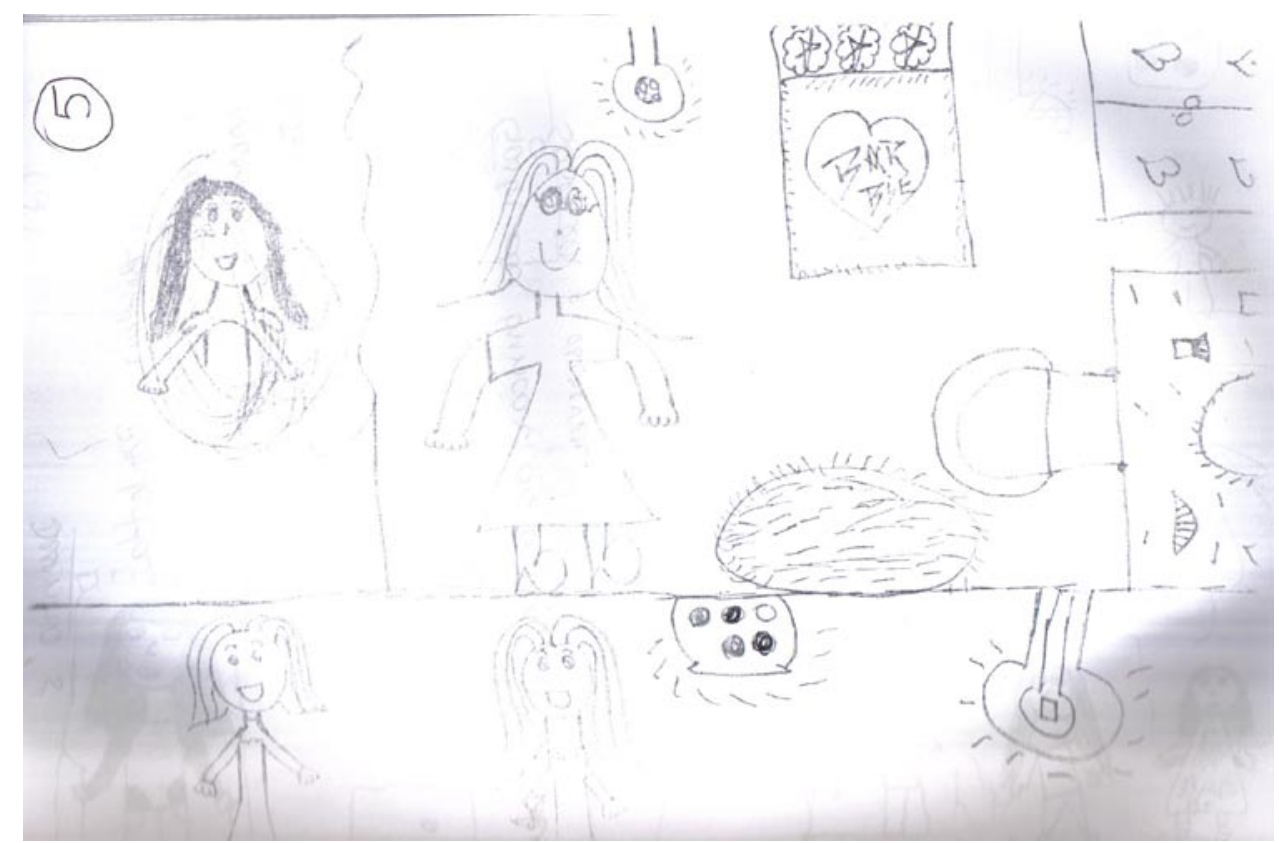

Criança 05 
A CULTURA DO CONSUMO E A EROTIZAÇÃO NA INFÂNCIA
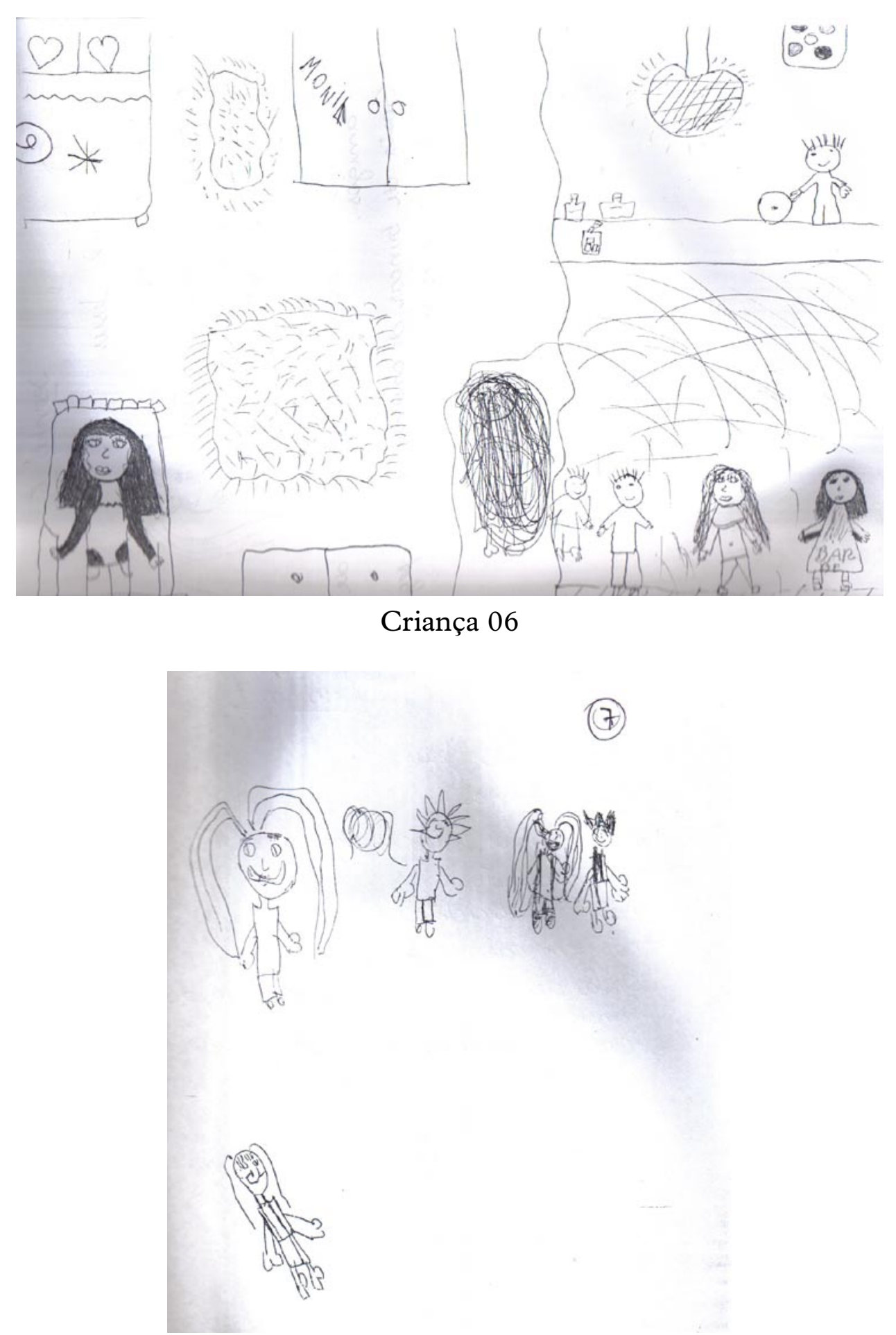

Criança 07 